Supporting Information

\title{
Systematic Differences between Current Molecular Dynamics Force Fields to Represent Local Properties of Intrinsically Disordered Proteins
}

\author{
Lei Yu, ${ }^{1}$ Da-Wei Li, ${ }^{2}$ and Rafael Brüschweiler ${ }^{1,2,3^{*}}$ \\ ${ }^{1}$ Department of Chemistry and Biochemistry, The Ohio State University, Columbus, Ohio 43210, \\ USA \\ ${ }^{2}$ Campus Chemical Instrument Center, The Ohio State University, Columbus, Ohio 43210, USA \\ ${ }^{3}$ Department of Biological Chemistry and Pharmacology, The Ohio State University, Columbus, \\ Ohio 43210, USA
}

*To whom correspondence should be addressed:

Rafael Brüschweiler, Ph.D., E-mail: bruschweiler.1@osu.edu 
This PDF file includes:

Tables S1, S2

Figures S1 - S3 
Table S1. Protein force fields with residue-specific corrections, $J$-couplings used in validation, and cumulative simulation lengths.

\begin{tabular}{c|c|c}
\hline force field & $\begin{array}{c}\text { peptides/IDPs with } J- \\
\text { couplings }\end{array}$ & $\begin{array}{c}\text { cumulative simulation length } \\
(\mu \mathrm{s})\end{array}$ \\
\hline ff12SB-cMAP $^{1}$ & No $J$-coupling comparison & N.A. \\
\hline ff19SB $^{2}$ & blocked amino acids, Ala 5 & 5 \\
\hline ff14IDPSFF $^{3}$ & $\begin{array}{c}\text { RS peptide, HEWL19, HIV-1 } \\
\text { Rev, amyloid- } \beta, \text { pdE- } \gamma\end{array}$ & 5 \\
\hline CHARMM36IDPSFF $^{4}$ & $\begin{array}{c}\text { Ala }, \text { Ala }, \text { amyloid- } \beta, \text { drkN } \\
\text { SH3, Histatin-5 }\end{array}$ & \\
\hline ESFF1 $^{5}$ & $\begin{array}{c}\text { tripeptides, RS peptide, } \\
\text { Histatin-5, HIV-1 Rev, } \\
\text { amyloid- } \beta, \text { drkN SH3, } \alpha- \\
\text { synuclein }\end{array}$ & \\
\hline RSFF1 $^{6}$ & blocked amino acids & $\sim 1$ \\
\hline RSFF2 $^{7,8}$ & blocked amino acids \\
& dipeptides & $\sim 1^{7} ; 1^{8}$ \\
\hline RSFF2C $^{9}$ & Histatin-5, HIV-1 Rev & 1 \\
\hline DES-Amber $^{10}$ & drkN SH3, $\alpha-$-synuclein, \\
& amyloid- $\beta$ & 30 \\
\hline
\end{tabular}


Table S2. Quantitative comparison using experimental NMR scalar ${ }^{3} J\left(\mathrm{H}^{\mathrm{N}}, \mathrm{H} \alpha\right)$-coupling constants of $\alpha$-synuclein and amyloid- $\beta$ peptides.

\begin{tabular}{|c|c|c|c|c|}
\hline \multirow[t]{2}{*}{ force field } & \multicolumn{2}{|c|}{$\alpha$-synuclein } & \multicolumn{2}{|c|}{ amyloid- $\beta$} \\
\hline & RMSD (Hz) $)^{\mathrm{a}}$ & $\mathrm{R}^{\mathrm{b}}$ & RMSD (Hz) & $\mathrm{R}^{\mathrm{b}}$ \\
\hline $\mathrm{nmr} 2$ & 0.46 & 0.79 & 0.63 & 0.68 \\
\hline ff14SB & 1.28 & 0.47 & 1.06 & 0.20 \\
\hline $\mathrm{C} 36 \mathrm{~m}$ & 1.09 & 0.39 & 0.85 & 0.59 \\
\hline ff99SB-disp & 1.17 & 0.64 & 0.96 & 0.49 \\
\hline ff14IDPSFF & $0.55^{5}$ & 1 & $0.78^{3}$ & 1 \\
\hline CHARMM36IDPSFF $^{4}$ & 7 & 7 & 0.56 & 7 \\
\hline $\mathrm{ESFF}^{5}$ & 0.67 & 1 & 0.58 & 1 \\
\hline DES-Amber ${ }^{10}$ & 0.73 & 0.76 & 0.67 & 0.76 \\
\hline
\end{tabular}

${ }^{\text {a }}$ Root-mean-square deviation (RMSD) of back-calculated vs. experimental ${ }^{3} J\left(\mathrm{H}^{\mathrm{N}}, \mathrm{H} \alpha\right)$-couplings b Pearson correlation coefficient R between back-calculated vs. experimental ${ }^{3} J\left(\mathrm{H}^{\mathrm{N}}, \mathrm{H} \alpha\right)$ couplings

Note: Results for ff14IDPSFF, CHARMM36IDPSFF, ESFF1, and DES-Amber were taken from the literature. 

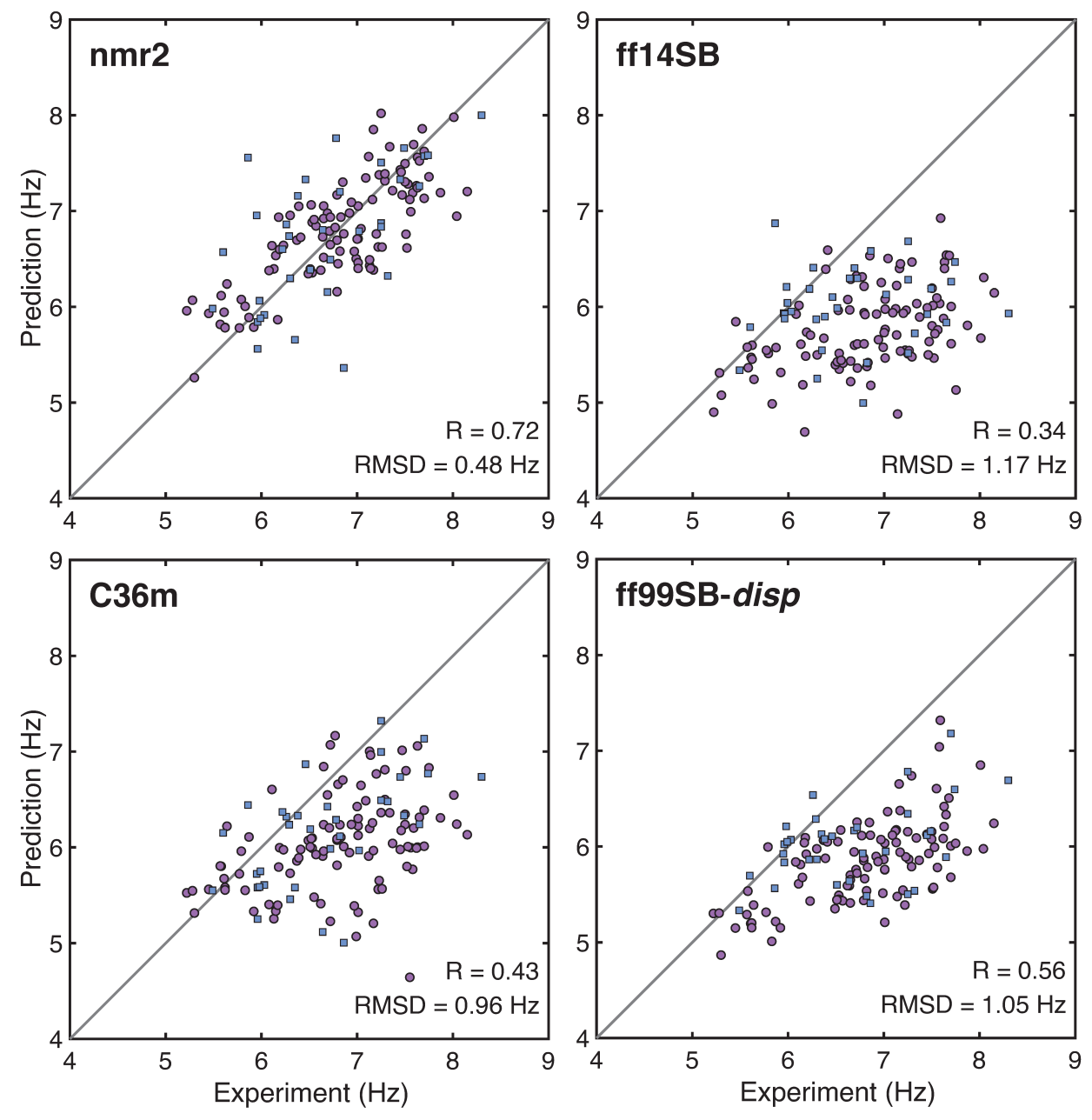

Figure S1. Predicted vs. experimental ${ }^{3} J\left(\mathrm{H}^{\mathrm{N}}, \mathrm{H} \alpha\right)$-coupling constants of disordered peptides for the critical assessment of the quality of recent MD force fields. ${ }^{3} J$-couplings of $\alpha$-synuclein residues (purple circles) and amyloid- $\beta$ residues (blue squares) were predicted from MD simulations using an alternative set of Karplus parameters $(A=8.69, B=-1.14, C=0.39)$ for the four force fields: nmr2, ff14SB, C36m, and ff99SB-disp. The predicted coupling constants were then averaged over the trajectories and compared with experimental values. Since these results are very similar to those of Figure 2 of the main text, the conclusions are insensitive to the exact Karplus parameters used. 

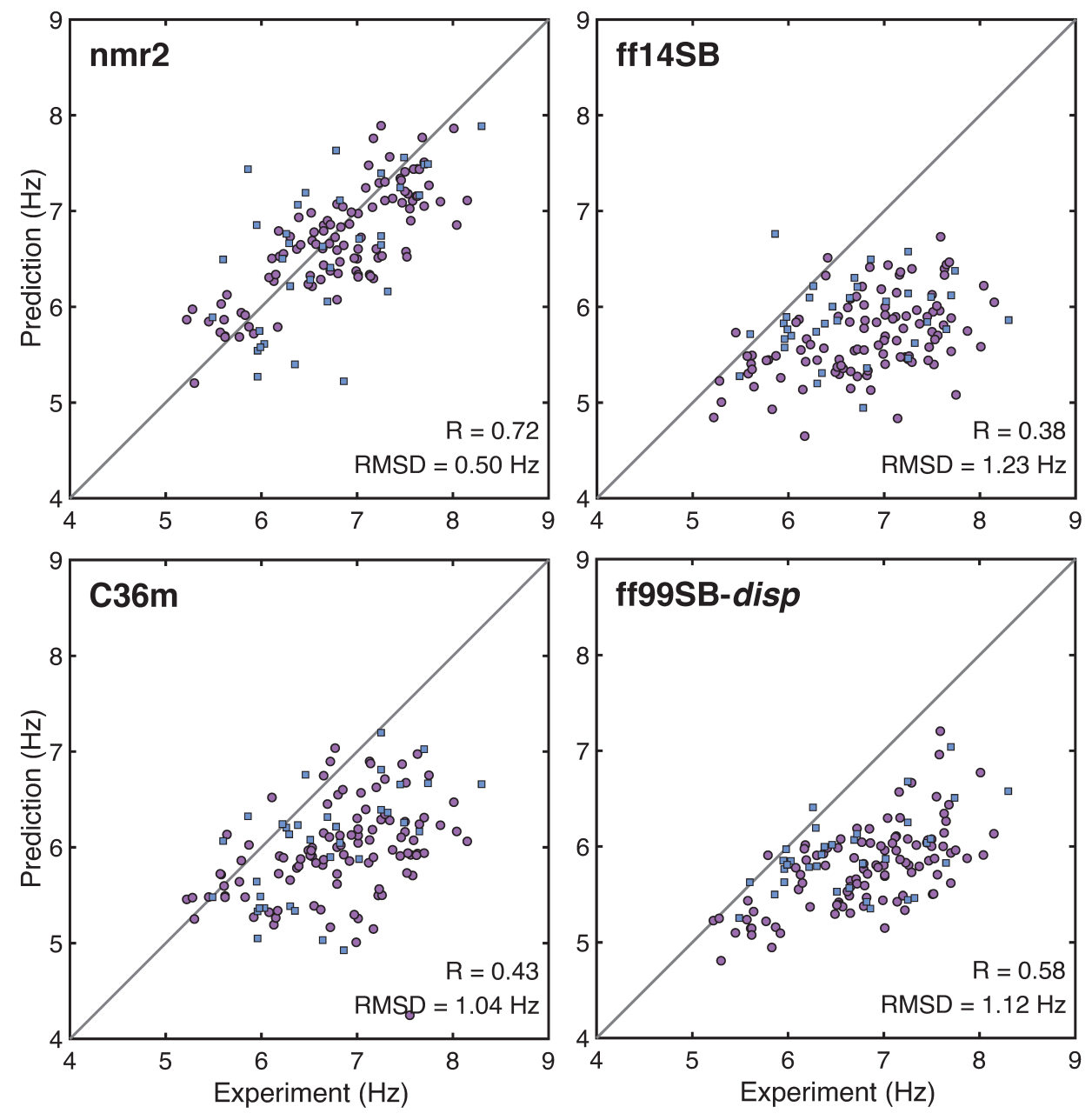

Figure S2. Predicted vs. experimental ${ }^{3} J\left(\mathrm{H}^{\mathrm{N}}, \mathrm{H} \alpha\right)$-coupling constants of disordered peptides for the critical assessment of the quality of recent MD force fields. ${ }^{3} J$-couplings of $\alpha$-synuclein residues (purple circles) and amyloid- $\beta$ residues (blue squares) were predicted from MD simulations using an alternative set of Karplus parameters $(A=8.40, B=-1.36, C=0.33)$ for the four force fields: nmr2, ff14SB, C36m, and ff99SB-disp. The predicted coupling constants were then averaged over the trajectories and compared with experimental values. Since these results are very similar to those of Figure 2 of the main text, the conclusions are insensitive to the exact Karplus parameters used. 

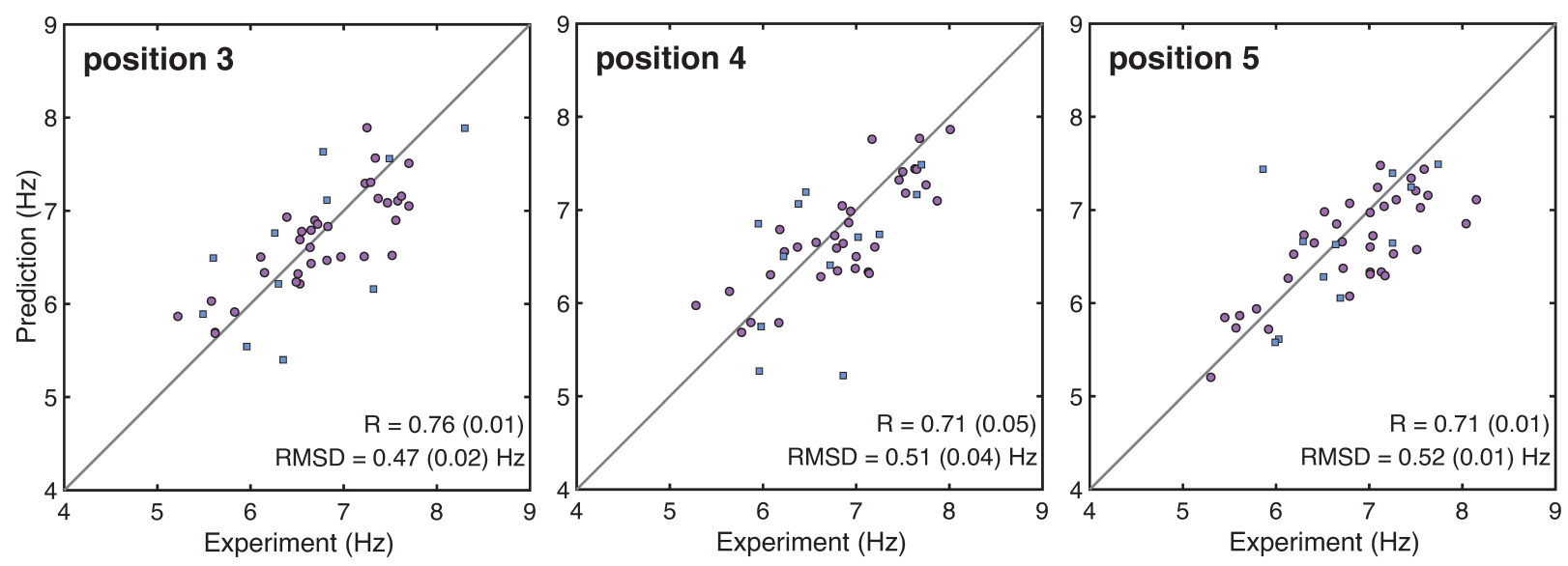

Figure S3. Predicted vs. experimental ${ }^{3} J\left(\mathrm{H}^{\mathrm{N}}, \mathrm{H} \alpha\right)$-coupling constants of disordered peptides for the assessment of the effect of the position 3,4 , or 5 of a residue in the peptide sequence. ${ }^{3} J$ couplings of $\alpha$-synuclein residues (purple circles) and amyloid- $\beta$ residues (purple squares) were predicted from MD simulations using the Karplus relationship (Eq. (1)) for the nmr2 force field. The predicted coupling constants were then averaged over the trajectories and compared with experimental values. Standard deviations in the parentheses were estimated by block averaging of the trajectories in blocks of 250-ns ( $\alpha$-synuclein) or 500-ns (amyloid- $\beta$ ) lengths. The similarly good ${ }^{3} J$-coupling prediction for all three residue positions 3,4 , and 5 in the heptapeptides suggests that there is not a significant position dependence. 


\section{References}

1. Perez, A.; MacCallum, J. L.; Brini, E.; Simmerling, C.; Dill, K. A., Grid-based backbone correction to the ff12SB protein force field for implicit-solvent simulations. J. Chem. Theory Comput. 2015, 11 (10), 4770-4779.

2. Tian, C.; Kasavajhala, K.; Belfon, K. A. A.; Raguette, L.; Huang, H.; Migues, A. N.; Bickel, J.; Wang, Y.; Pincay, J.; Wu, Q.; Simmerling, C., ff19SB: Amino-Acid-Specific Protein Backbone Parameters Trained against Quantum Mechanics Energy Surfaces in Solution. J. Chem. Theory Comput. 2020, 16 (1), 528-552.

3. Henriques, J.; Cragnell, C.; Skepö, M., Molecular Dynamics Simulations of Intrinsically Disordered Proteins: Force Field Evaluation and Comparison with Experiment. J. Chem. Theory Comput. 2015, 11 (7), 3420-3431.

4. Liu, H.; Song, D.; Zhang, Y.; Yang, S.; Luo, R.; Chen, H.-F., Extensive tests and evaluation of the CHARMM36IDPSFF force field for intrinsically disordered proteins and folded proteins. Phys. Chem. Chem. Phys. 2019, 21 (39), 21918-21931.

5. Song, D.; Liu, H.; Luo, R.; Chen, H.-F., Environment-Specific Force Field for Intrinsically Disordered and Ordered Proteins. J. Chem. Inf. Model. 2020, 60 (4), 2257-2267.

6. Jiang, F.; Zhou, C.-Y.; Wu, Y.-D., Residue-specific force field based on the protein coil library. RSFF1: modification of OPLS-AA/L. J. Phys. Chem. B 2014, 118 (25), 6983-6998.

7. Zhou, C.-Y.; Jiang, F.; Wu, Y.-D., Residue-Specific Force Field Based on Protein Coil Library. RSFF2: Modification of AMBER ff99SB. J. Phys. Chem. B 2015, 119 (3), $1035-$ 1047.

8. Li, S.; Elcock, A. H., Residue-Specific Force Field (RSFF2) Improves the Modeling of Conformational Behavior of Peptides and Proteins. J. Phys. Chem. Lett. 2015, 6 (11), 21272133.

9. Kang, W.; Jiang, F.; Wu, Y.-D., Universal Implementation of a Residue-Specific Force Field Based on CMAP Potentials and Free Energy Decomposition. J. Chem. Theory Comput. 2018, 14 (8), 4474-4486.

10. Piana, S.; Robustelli, P.; Tan, D.; Chen, S.; Shaw, D. E., Development of a Force Field for the Simulation of Single-Chain Proteins and Protein-Protein Complexes. J. Chem. Theory Comput. 2020, 16 (4), 2494-2507. 